\title{
Enhanced Eating Competence Is Associated with Improved Diet Quality and Cardiometabolic Profile in Finnish Adults with Increased Risk of Type 2 Diabetes
}

\author{
Kirsikka Aittola ${ }^{1, *} \mathbb{0}$, Leila Karhunen ${ }^{1}\left(\mathbb{D}\right.$, Reija Männikkö ${ }^{1,2}$, Elina Järvelä-Reijonen ${ }^{1}$, Santtu Mikkonen ${ }^{3}{ }^{(0)}$, \\ Pilvikki Absetz ${ }^{1,4}$, Marjukka Kolehmainen ${ }^{1}{ }^{(\mathbb{D}}$, Ursula Schwab ${ }^{1,2}{ }^{\circledR}$, Marja Harjumaa ${ }^{5}$, Jaana Lindström ${ }^{6}{ }^{(0)}$, \\ Timo Lakka ${ }^{7,8,9}$, Tanja Tilles-Tirkkonen ${ }^{1,+}+\mathbb{C}$ and Jussi Pihlajamäki ${ }^{1,2, \dagger}$
}

1 Institute of Public Health and Clinical Nutrition, School of Medicine, University of Eastern Finland, 70211 Kuopio, Finland; Leila.Karhunen@uef.fi (L.K.); Reija.Mannikko@terveystalo.com (R.M.); Elina.Jarvela-Reijonen@uef.fi (E.J.-R.); Pilvikki.Absetz@gmail.com (P.A.); Marjukka.Kolehmainen@uef.fi (M.K.); Ursula.Schwab@uef.fi (U.S.); Tanja.Tilles-Tirkkonen@uef.fi (T.T.-T.); Jussi.Pihlajamaki@uef.fi (J.P.)

2 Endocrinology and Clinical Nutrition, Department of Medicine, Kuopio University Hospital, 70029 Kuopio, Finland

3 Department of Applied Physics, University of Eastern Finland, 70211 Kuopio, Finland; Santtu.Mikkonen@uef.fi

check for updates

Citation: Aittola, K.; Karhunen, L.; Männikkö, R.; Järvelä-Reijonen, E.; Mikkonen, S.; Absetz, P.;

Kolehmainen, M.; Schwab, U.; Harjumaa, M.; Lindström, J.; et al. Enhanced Eating Competence Is Associated with Improved Diet Quality and Cardiometabolic Profile in Finnish Adults with Increased Risk of Type 2 Diabetes. Nutrients 2021, 13, 4030. https://doi.org/10.3390/ nu13114030

Academic Editor: Maria Luz Fernandez

Received: 19 September 2021 Accepted: 4 November 2021 Published: 11 November 2021

Publisher's Note: MDPI stays neutral with regard to jurisdictional claims in published maps and institutional affiliations.

Copyright: (c) 2021 by the authors. Licensee MDPI, Basel, Switzerland. This article is an open access article distributed under the terms and conditions of the Creative Commons Attribution (CC BY) license (https:/ / creativecommons.org/licenses/by/ $4.0 /)$.
4 Collaborative Care Systems Finland, 00270 Helsinki, Finland

5 VTT Technical Research Centre of Finland Ltd., 02044 Espoo, Finland; Marja.Harjumaa@salivirta.fi

6 Department of Public Health and Welfare, National Institute for Health and Welfare, 00271 Helsinki, Finland; Jaana.Lindstrom@thl.fi

7 Institute of Biomedicine, School of Medicine, University of Eastern Finland, 70211 Kuopio, Finland; Timo.Lakka@uef.fi

8 Department of Clinical Physiology and Nuclear Medicine, Kuopio University Hospital, 70029 Kuopio, Finland

9 Kuopio Research Institute of Exercise Medicine, 70100 Kuopio, Finland

* Correspondence: Kirsikka.Aittola@uef.fi; Tel.: +358-50-5167269

+ These authors are joint senior authors on this work.

Abstract: Eating competence (EC) is characterized by positive attitudes towards food and eating, having regular meals, eating a variety of foods, and internally regulated eating. We investigated the associations of changes in EC with changes in lifestyle, anthropometrics and biomarkers of glucose and lipid metabolism in 2291 adults at increased risk of type 2 diabetes as part of the StopDia study conducted in primary healthcare. EC and diet quality were assessed with validated digital questionnaires. During the intervention, the participants received either (1) the digital lifestyle intervention, (2) the combined digital and face-to-face group-based lifestyle intervention, or (3) standard care. EC increased among the participants independent of the intervention type. Increase in EC was associated with an increase in diet quality, high-density lipoprotein (HDL) cholesterol, and with a decrease in body mass index and waist circumference, regardless of baseline EC. Of the subdomains of EC, the contextual skills, food acceptance and eating attitudes were associated with various of these changes. Our results thus suggest that EC could be a potential target in lifestyle interventions aiming to improve the cardiometabolic health of people at type 2 diabetes risk.

Keywords: adiposity; diet; diet quality; eating behavior; glucose metabolism; health care; lifestyle; lipid metabolism; obesity; overweight; prevention; type 2 diabetes

\section{Introduction}

Type 2 diabetes (T2D), a major health and economic burden in the world, can be prevented among those at increased risk with lifestyle interventions that include intensive nutrition and physical activity counselling [1-4]. However, the impact of these interventions depends on how well new lifestyle habits, including a health promoting diet, are 
adopted [5]. Moreover, the role of changes in eating behavior remains unclear. A novel approach to support healthy lifestyle could be to focus on eating competence (EC) as defined in the Satter Eating Competence Model [6-9]. According to ecSatter, EC comprises an individual's flexible and positive attitudes towards food and eating, acceptance of a variety of foods, internal regulation of eating and contextual skills around daily meals [6].

The EC has been linked to many health-related parameters, such as an improved diet quality $[7,8,10-13]$ and weight management in different populations [7,10,13-15]. Our previous study showed that being eating competent was strongly associated with a better diet quality, a decreased likelihood of being obese or having an increased waist circumference, metabolic syndrome or newly diagnosed T2D in adults at increased risk of T2D [9]. However, so far, previous findings have mainly been supported by cross-sectional studies.

Eating attitudes and behaviors begin to develop during childhood and change throughout life [6] suggesting that EC can potentially be influenced by lifestyle interventions. However, to the best of our knowledge, there have so far been only a few studies dealing with the effects of lifestyle interventions on EC. One of these studies showed that EC increased and was associated with reduced body weight during a 1-year lifestyle intervention aimed at weight loss [12]. However, no changes in EC were found in other two 8-week interventions [16,17], but after a 32-week follow-up one subdomain of EC, food acceptance, improved in the intervention consisting of group-based acceptance and commitment therapy [17]. On the other hand, it is noteworthy that some aspects of EC, such as eating attitudes and internal regulation, might even decrease temporarily during lifestyle intervention [12], most likely due to increased awareness of those features. Thus, the results of earlier studies suggest that EC could be influenced by lifestyle interventions. Nevertheless, there is no previous evidence on the associations of changes in EC with changes in cardiometabolic risk factors.

Therefore, we utilized the data from the Stop Diabetes (StopDia) study [18] to investigate whether EC changed during a 1-year lifestyle intervention in adults at increased risk of T2D. We then examined whether changes in EC were associated with changes in diet quality, physical activity, overall adiposity, abdominal adiposity or glucose and lipid metabolism.

\section{Materials and Methods}

\subsection{Study Design}

This study is a secondary analysis of the StopDia study that included a 1-year parallel randomized controlled trial (RCT) (ClinicalTrials.gov registration no. NCT03156478) investigating the effects of a lifestyle intervention delivered via digital app and group counselling on risk factors for T2D in individuals at risk of T2D [18]. A detailed protocol of the StopDia study has been described earlier [18]. The StopDia study was conducted in primary healthcare as part of its routine actions between April 2017 and February 2019. The participants with entire data on EC were included in the study.

\subsection{Participants}

The participants at increased risk of T2D were recruited to the StopDia study using the StopDia Digital Screening Tool [18], including questions from the Finnish Diabetes Risk Score (FINDRISC) [19]. The inclusion criteria for the StopDia study were: (1) age of 18 to 70 years; (2) at least 12 points in the FINDRISC or previous gestational diabetes or repeated impaired fasting glucose or impaired glucose; (3) residence in one of the study provinces (Northern Savo, Southern Carelia or Päijät-Häme); (4) possibility to use a computer or smart device with an Internet connection; (5) having a personal cell-phone number; and (6) adequate Finnish language skills. Individuals with previously diagnosed type 1 or 2 diabetes, pregnancy or current cancer treatment were excluded [18].

First, potential participants according to the screening tool were invited to participate in the study and were referred to a nurse's visit at their local primary healthcare center [18]. There a nurse checked that the participants were suitable for the study, the participants 
signed an informed consent and a trained nurse performed clinical measurements and referred the participants to laboratory measurements at local laboratories. Additionally, the participants completed online the StopDia Digital Questionnaire (LimeSurvey $\mathrm{GmbH}$, Hamburg, Germany). Finally, 2909 eligible individuals were digitally randomized to the StopDia study: 967 of them were randomized to the digital, 971 to the combined digital and group-based lifestyle intervention, and 971 to the control groups (Figure A1). After randomization, the participants were informed by e-email of their study group as well as the content of the intervention [18].

Participants with missing data on EC either at baseline or at 1 year were excluded from the analyses $(n=618,21 \%)$. Therefore, altogether 2291 participants comprised the population of this study (Figure A1). Those who were excluded were younger (51 vs. 56 years), less educated (60\% vs. $67 \%$ with highest education), and less eating competent ( $29 \%$ vs. $40 \%$ ) and had a higher BMI ( $32 \mathrm{vs.} 31 \mathrm{~kg} / \mathrm{m}^{2}$ ) at baseline compared to those who participated to assessments at both time points (all $p<0.05$ ).

\subsection{Lifestyle Interventions}

The general lifestyle goals of the intervention were to improve diet, increase physical activity, decrease sedentary behavior, improve sleep, cease smoking, and moderate alcohol consumption [18].

Both intervention groups (digital; combined digital and group-based) obtained access to the BitHabit app and were instructed to use it throughout the one-year intervention period $[18,20]$. The habit formation and self-determination theories-based app included nearly 500 simple behavioral suggestions intended to support habit formation for a healthier lifestyle, including eating behaviors and attitudes. The participants were able to browse, select, and track habits from different lifestyle categories.

The combined digital and group-based group additionally received lifestyle group counselling that included six pre-structured group meetings to support behavior change and was based on the self-determination theories. The group meetings were organized in local healthcare centers by trained nurses or nutritionists. Between the meetings, lifestyle changes were supported by homework materials. Some aspects included in the ecSatter were considered in the digital and in the group-based intervention such as paying attention to eating and meal rhythm, planning meals, eating a variety of foods, experimenting new foods, and having flexible attitude towards food. In addition, group meetings addressed themes such as daily rhythm, health-promoting diet, exercise, lifestyle changes, and success in them [18].

The control group received brief written information about lifestyle risk factors of type 2 diabetes and recommendations on a healthy diet and physical activity. Participants in all groups obtained the results of their own laboratory measurements after their laboratory visits at baseline and 1-year follow-up.

At the end of the intervention, participants were reminded to book an appointment for the 1-year follow-up visits, which included the same measurements as at the baseline.

\subsection{Assessments}

\subsubsection{Eating Competence (EC)}

EC was measured with the 16-item Satter Eating Competence Inventory $2.0^{\mathrm{TM}}(\mathrm{ecSI}$ $\left.2.0^{\mathrm{TM}}\right)[6,7,10,21,22]$, which has been validated among general and low-income US people $[7,22,23]$ and used in intervention studies among people with obesity [12,16], also in Finland $[17,24]$. The inventory contains six items to determine eating attitudes (e.g., 'I enjoy food and eating'), five to contextual skills around meals (e.g., 'I have regular meals'), three to food acceptance (e.g., 'I experiment with new food and learn to like it'), and two to internal regulation of hunger and satiety (e.g.,' I eat until I feel satisfied'). The response options for the items were always, often, sometimes, rarely and never, and scored 3, 2, 1, 0 and 0 , respectively [22]. Items were summed to yield a total score of $\mathrm{EC}$ ranging from 0 to 48 and to yield four sub-scores [25]. A person scoring 32 or more was defined as an eating 
competent one [22]. Cronbach's alpha coefficient was 0.84 for the total score of ecSI $2.0^{\mathrm{TM}}$, 0.77 for eating attitudes, 0.76 for contextual skills, 0.62 for food acceptance and 0.72 for internal regulation at baseline. The respective values at 1 -year follow-up were $0.85,0.78$, $0.77,0.65$ and 0.76 .

\subsubsection{Diet Quality}

Quality of diet was assessed by the Healthy Diet Index (HDI) [26]. The HDI assesses the adherence to a healthy diet according to the Finnish nutrition recommendations [27] and prevention of T2D with a scale ranging from 0 (lowest quality) to 100 (highest quality). It comprises of the following seven domains, which are weighted depending on their importance in a diet to prevent T2D: 1 . meal pattern (score range 0-10); 2 . fruit and vegetables $(0-20) ; 3$. grains $(0-20) ; 4$. fats $(0-15) ; 5$. fish and meat $(0-10) ; 6$. dairy $(0-10)$; and 7. snacks and treats including beverages (0-15) [26].

\subsubsection{Physical Activity}

The total physical activity was assessed with questions of conditioning and everyday physical activity, and physical activity during work trips (hour/week) [18]. The total duration of physical activity was calculated by multiplying the number of sessions of physical activity per week by the duration of each session of physical activity.

\subsubsection{Anthropometrics}

Height (without shoes), weight (in light indoor clothing) and waist circumference (midpoint between the lowest ribs and iliac bone) were measured by the nurses and body mass index (BMI, $\mathrm{kg} / \mathrm{m}^{2}$ ) was calculated.

\subsubsection{Biochemical Measurements}

Laboratory measurements were taken after a $12 \mathrm{~h}$ overnight fast at local healthcare centers and analyzed in their designated quality-controlled laboratories, expect plasma insulin concentration was analyzed in the laboratory of the University of Eastern Finland. The measurements contained fasting, $30 \mathrm{~min}$, and $2 \mathrm{~h}$ plasma glucose and insulin concentrations from a $2 \mathrm{~h}$ oral glucose tolerance test (OGTT) after the ingestion of $75 \mathrm{~g}$ of glucose, blood glycated hemoglobin ( $\mathrm{HbA1c}$ ) as well as fasting plasma total cholesterol, low-density lipoprotein (LDL) cholesterol, high-density lipoprotein (HDL) cholesterol and triglyceride concentrations. Peripheral insulin sensitivity was measured by calculating the Matsuda insulin sensitivity index (MatsudaISI) based on glucose and insulin concentrations at 0 , 30 and $120 \mathrm{~min}$ of the $2 \mathrm{~h}$ OGTT [28,29]. Impaired fasting glucose or impaired glucose tolerance was determined by the American Diabetes Association classification [30].

\subsubsection{Other Assessments}

Age (years) was calculated based on time of birth and study province and education were based on responses of the StopDia Digital Questionnaire. Education was categorized as "low" (basic education), "medium" (intermediate education) or "high" (higher education).

\subsection{Statistical Analysis}

The study data were managed using REDCap electronic data capture tools hosted at the University of Eastern Finland [31]. Statistical analyses were performed with the SPSS Statistics, version 27.0 (IBM, Armonk, NY, USA). Continuous variables are presented as means ( $\pm \mathrm{SD}$, standard deviation), and categorical variables as frequencies (\%). Two-sided $p$ values $<0.05$ were considered statistically significant. We compared baseline characteristics among the groups for continuous normally distributed variables by ANOVA, for nonnormally distributed variables by the Kruskal-Wallis $H$ test and for categorical variables by the $\chi 2$. Cronbach's alpha coefficients were used to assess internal consistency of the scores of ecSI $2.0^{\mathrm{TM}}$. 
Linear mixed-effects models with a maximum likelihood estimation were used to test for the effects of intervention and time on EC. We adjusted the models for sex, age and study province at baseline and included main effects for follow-up time and for study group $x$ follow-up time interaction. These variables were determined as covariates a priori as they may influence EC and other outcome variables. The follow-up time (number of days) was treated as a continuous variable to allow for a small variation in follow-up time between the participants and the different measurements. To study the association of the EC with outcome variables, we entered the total EC score at both time points (baseline, one year) to the model. It was further adjusted for educational level as it may influence EC [9]. Analyses of lipids were also adjusted for medication use for hypercholesterolemia at baseline. To study the independent effect of the change in EC on outcomes, we adjusted the model for the baseline EC score. We also wanted to study independently the effects of the subdomains of EC on outcomes, so they were separately entered in the model without the EC total score. Sub-scores were additionally adjusted for corresponding baseline sub-scores. Regression coefficients, 95\% CIs along with $p$ values after adjustments and having study group-time interaction in the model, are reported in the tables.

\section{Results}

\subsection{Characteristics of Particpants}

The baseline characteristics of participants are presented in Table 1. The mean (SD) of age was 56 (10) years, and $81 \%$ of participants were women. Altogether, $1189(52 \%)$ of participants had obesity $\left(\mathrm{BMI}>30 \mathrm{~kg} / \mathrm{m}^{2}\right)$, and $1241(54 \%)$ had impaired fasting glucose or impaired glucose tolerance. There were no differences in baseline characteristics among the study groups.

Table 1. Baseline characteristics of participants.

\begin{tabular}{|c|c|c|c|}
\hline Descriptive Variable & Control $(n=778)$ & Digital $(n=751)$ & $\begin{array}{c}\text { Combined Digital and } \\
\text { Group-Based } \\
(n=762)\end{array}$ \\
\hline Sex, women & $628(81 \%)$ & $601(80 \%)$ & $617(81 \%)$ \\
\hline Age, years & $56.2(9.3)$ & $55.8(9.6)$ & $56.4(9.6)$ \\
\hline Native country, Finland & $771(99 \%)$ & $744(99 \%)$ & $756(99 \%)$ \\
\hline $\begin{array}{l}\text { Study province } \\
\text { Northern Savo } \\
\text { Southern Carelia } \\
\text { Päijät-Häme }\end{array}$ & $\begin{array}{l}220(28 \%) \\
204(26 \%) \\
354(46 \%)\end{array}$ & $\begin{array}{l}200(27 \%) \\
213(28 \%) \\
338(45 \%)\end{array}$ & $\begin{array}{l}216(28 \%) \\
210(28 \%) \\
336(44 \%)\end{array}$ \\
\hline $\begin{array}{l}\text { Education level } \\
\text { Low } \\
\text { Medium } \\
\text { High } \\
\end{array}$ & $\begin{array}{c}53(7 \%) \\
211(27 \%) \\
514(66 \%) \\
\end{array}$ & $\begin{array}{c}40(5 \%) \\
206(27 \%) \\
505(67 \%)\end{array}$ & $\begin{array}{c}64(8 \%) \\
192(25 \%) \\
506(66 \%)\end{array}$ \\
\hline Total physical activity, h/week* & $10.4(11.1)$ & $10.2(9.0)$ & $9.7(8.6)$ \\
\hline Healthy Diet Index (range 0-100) * & $63.0(10.6)$ & $62.8(11.3)$ & $63.0(10.9)$ \\
\hline Use of cholesterol lowering medication & $141(18 \%)$ & $129(17 \%)$ & $131(17 \%)$ \\
\hline Body weight, $\mathrm{kg}$ & $86.4(16.6)$ & $85.4(16.9)$ & $85.2(17.3)$ \\
\hline Body mass index, $\mathrm{kg} / \mathrm{m}^{2}$ & $31.1(5.4)$ & $30.7(5.3)$ & $30.7(5.4)$ \\
\hline Waist circumference, $\mathrm{cm}$ & $102(13)$ & $100(13)$ & $101(13)$ \\
\hline Fasting plasma glucose, $\mathrm{mmol} / \mathrm{L}^{*}$ & $5.60(0.56)$ & $5.55(0.56)$ & $5.59(0.57)$ \\
\hline 2-h plasma glucose, $\mathrm{mmol} / \mathrm{L}^{*}$ & $6.38(1.76)$ & $6.26(1.68)$ & $6.45(1.73)$ \\
\hline
\end{tabular}


Table 1. Cont.

\begin{tabular}{cccc}
\hline Descriptive Variable & Control $(\boldsymbol{n = 7 7 8 )}$ & Digital ( $\boldsymbol{n = 7 5 1 )}$ & $\begin{array}{c}\text { Combined Digital and } \\
\text { Group-Based } \\
(\boldsymbol{n}=\mathbf{7 6 2})\end{array}$ \\
\hline EC total score (range 0-48) & & $29.6(7.2)$ \\
Median (IQR) & $29.8(7.0)$ & $29.8(6.9)$ & $30(25-34)$ \\
Eating attitudes (range 0-18) & $30(26-34)$ & $30(25-35)$ & $13.1(3.2)$ \\
Median (IQR) & $13.1(3.0)$ & $13(11-15)$ & $13(11-15)$ \\
Contextual skills (range 0-15) & $13(11-15)$ & $8.1(3.1)$ & $8.1(3.1)$ \\
Median (IQR) & $8.2(3.2)$ & $9(6-10)$ & $8(6-10)$ \\
Food acceptance (range 0-9) & $9(6-10)$ & $4.5(1.9)$ & $4.5(2.0)$ \\
Median (IQR) & $4.4(1.9)$ & $5(3-6)$ & $4(3-6)$ \\
Internal regulation (range 0-6) & $4(3-6)$ & $4.0(1.4)$ & $4.9(1.4)$ \\
\hline Median (IQR) & $4.0(1.4)$ & $4(3-5)$ & $4(3-5)$ \\
\hline
\end{tabular}

Data are frequencies (\%) or means (standard deviations, SD). IQR = interquartile range. Eating competence (EC) was measured by the Satter Eating Competence Inventory 2.0 ${ }^{\mathrm{TM}}$; * Data not available for all participants, $n=2252$ for physical activity, $n=2261$ for Healthy Diet Index, $n=2290$ for waist circumference, $n=2284$ for fasting plasma glucose, $n=2282$ for $2 \mathrm{~h}$ plasma glucose.

\subsection{Eating Competence at Baseline and Change in Eating Competence over One Year}

The mean (SD) of the EC total score at baseline was 29.7 (7), and there was no difference in the score between the study groups (Table 1 ). The EC total score increased by 0.5 points $(2 \%)$ among participants over one year $(\beta=0.64,95 \%$ CI $0.30-0.97, p<0.001$ for time) (Figure 1, Panel A), increasing 0.4 in the digital, 0.5 in the combined digital and groupbased and 0.7 in the control group with no difference in the change of the score between the study groups. Altogether $909(40 \%)$ of the participants were defined as eating competent at baseline and $989(43 \%)$ after 1 year with no difference between the study groups.

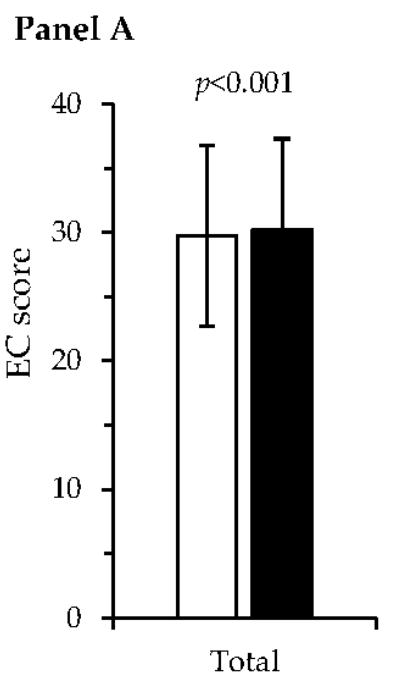

$$
\text { Panel B } \quad \text { Baseline } \mathbf{0} \text { 1-year follow-up }
$$

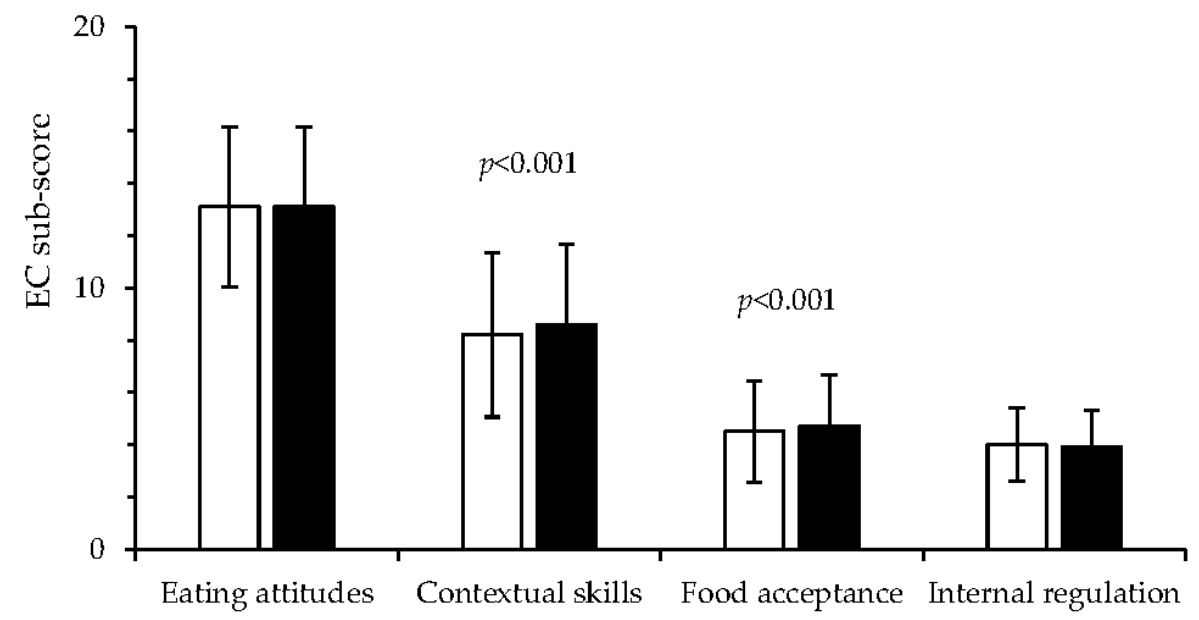

Figure 1. Panel A. Eating Competence (EC) total score (mean $\pm \mathrm{SD}$ ) increased between baseline and one year in the whole study group ( $p<0.001$ for time), but there were no differences between the study groups. Panel B. EC sub-scores (mean \pm SD) of contextual skills ( $p<0.001$ for time) and food acceptance $(p<0.001$ for time) increased between baseline and one year in the whole study group, but there were no differences between the study groups. Linear mixed effects model, $n=2291$.

Of EC sub-scores, contextual skills increased by 0.4 points $(5 \%, \beta=0.38,95 \%$ CI $0.22-0.54$, $p<0.001$ for time) and food acceptance by 0.2 points $(4 \%, \beta=0.21,95 \%$ CI $0.11-0.31, p=<0.001$ for time), whereas eating attitudes and internal regulation did not change (Figure 1, Panel B). There were no differences in the changes of the sub-scores between the study groups. 


\subsection{Change in Eating Competence Total Score Associated with Changes in Diet Quality and Physical Activity}

An increase in the EC total score was associated with an increase in HDI, its subdomains 'meal pattern', 'fruit and vegetables', 'fats', 'fish and meat' and 'snacks and treats' as well as total physical activity, all adjusted for age, sex, study province and educational level (Table 2, Figure 2). These associations, except those with the HDI subdomain 'fats' and total physical activity, remained statistically significant after further adjustment for the EC total score at baseline (Table 2).

Table 2. Associations of changes in eating competence (EC) total score with changes in lifestyle and metabolic factors over one year.

\begin{tabular}{|c|c|c|c|c|}
\hline Outcome Measures & $\begin{array}{c}\text { Model 1 } \\
\beta(95 \% \text { CI })\end{array}$ & $p$ Value & $\begin{array}{c}\text { Model } 2 \\
\beta(95 \% \text { CI })\end{array}$ & $p$ Value \\
\hline \multicolumn{5}{|l|}{ Diet Quality } \\
\hline Healthy Diet Index, points & $0.25(0.21$ to 0.30$)$ & $<0.001$ & $0.18(0.13$ to 0.24$)$ & $<0.001$ \\
\hline Meal pattern & 0.03 (0.02 to 0.03$)$ & $<0.001$ & $0.02(0.01$ to 0.02$)$ & $<0.001$ \\
\hline Fruit and vegetables & $0.15(0.12$ to 0.17$)$ & $<0.001$ & $0.10(0.07$ to 0.13$)$ & $<0.001$ \\
\hline Grains & $0.01(-0.01$ to 0.03$)$ & 0.160 & $0.02(-0.01$ to 0.04$)$ & 0.273 \\
\hline Fats & $0.03(0.02$ to 0.04$)$ & $<0.001$ & $0.02(-0.001$ to 0.04$)$ & 0.059 \\
\hline Fish and meat & $0.03(0.02$ to 0.04$)$ & $<0.001$ & $0.02(0.01$ to 0.03$)$ & 0.001 \\
\hline Dairy & $-0.002(-0.01$ to 0.01$)$ & 0.601 & $-0.003(-0.02$ to 0.01$)$ & 0.660 \\
\hline Snacks and treats & 0.02 (0.01 to 0.03$)$ & $<0.001$ & $0.02(0.01$ to 0.04$)$ & 0.001 \\
\hline \multicolumn{5}{|l|}{ Physical activity } \\
\hline Total physical activity, h/week & 0.08 (0.04 to 0.12$)$ & $<0.001$ & $0.03(-0.03$ to 0.09$)$ & 0.291 \\
\hline \multicolumn{5}{|l|}{ Anthropometry } \\
\hline Body weight, kg & $\begin{array}{c}-0.06(-0.08 \text { to } \\
-0.03)\end{array}$ & $<0.001$ & $\begin{array}{c}-0.04(-0.07 \text { to } \\
-0.01)\end{array}$ & 0.008 \\
\hline Body mass index, $\mathrm{kg} / \mathrm{m}^{2}$ & $\begin{array}{c}-0.02(-0.03 \text { to } \\
-0.01)\end{array}$ & $<0.001$ & $\begin{array}{c}-0.01(-0.03 \text { to } \\
-0.004)\end{array}$ & 0.006 \\
\hline Waist circumference, $\mathrm{cm}$ & $\begin{array}{c}-0.10(-0.13 \text { to } \\
-0.06)\end{array}$ & $<0.001$ & $\begin{array}{c}-0.06(-0.10 \text { to } \\
-0.02)\end{array}$ & 0.001 \\
\hline \multicolumn{5}{|l|}{ Glucose metabolism } \\
\hline $\mathrm{HbA} 1 \mathrm{c}, \mathrm{mmol} / \mathrm{mol}$ & $-0.01(-0.02$ to 0.01$)$ & 0.259 & $-0.01(-0.03$ to 0.02$)$ & 0.616 \\
\hline Fasting plasma glucose, $\mathrm{mmol} / \mathrm{L}$ & $\begin{array}{c}-0.0004(-0.003 \text { to } \\
0.002)\end{array}$ & 0.706 & $\begin{array}{c}0.002(-0.002 \text { to } \\
0.005)\end{array}$ & 0.342 \\
\hline 2-h plasma glucose from OGTT, mmol/L & $-0.002(-0.01$ to 0.01$)$ & 0.623 & $0.01(-0.01$ to 0.02$)$ & 0.371 \\
\hline Fasting plasma insulin, $\mathrm{mU} / \mathrm{L}$ & $-0.04(-0.09$ to 0.005$)$ & 0.079 & $0.03(-0.04$ to 0.10$)$ & 0.450 \\
\hline Matsuda insulin sensitivity index & $0.04(0.01$ to 0.08$)$ & 0.011 & $0.02(-0.03$ to 0.06$)$ & 0.404 \\
\hline \multicolumn{5}{|l|}{ Lipid metabolism } \\
\hline Total cholesterol, mmol/L & $\begin{array}{c}0.001(-0.003 \text { to } \\
0.005)\end{array}$ & 0.614 & $\begin{array}{c}-0.001(-0.01 \text { to } \\
0.004)\end{array}$ & 0.727 \\
\hline LDL cholesterol, $\mathrm{mmol} / \mathrm{L}$ & $\begin{array}{c}-0.0001(-0.004 \text { to } \\
0.003)\end{array}$ & 0.972 & $\begin{array}{c}-0.002(-0.01 \text { to } \\
0.003)\end{array}$ & 0.506 \\
\hline HDL cholesterol, mmol/L & $0.002(0.001$ to 0.004$)$ & $<0.001$ & $0.002(0.001$ to 0.004$)$ & 0.005 \\
\hline Triglycerides, mmol/L & $\begin{array}{c}-0.004(-0.01 \text { to } \\
-0.001)\end{array}$ & 0.009 & $\begin{array}{c}-0.001(-0.005 \text { to } \\
0.003)\end{array}$ & 0.629 \\
\hline
\end{tabular}

The data are regression coefficients $(\beta)$ and their $95 \%$ confidence intervals (CI) for changes in outcomes from linear mixed-effects models and $p$ values for EC; OGTT = oral glucose tolerance test; Model 1 was adjusted for age, sex, study province, educational level and study group $\mathrm{x}$ follow-up time interaction (follow-up time between nurse visits, filling out questionnaires or laboratory visits). Measures of lipid metabolism were also adjusted for cholesterol-lowering medication; Model 2 was additionally adjusted for EC total score at baseline. 


\section{Lifestyle}

Healthy Diet Index, point

Meal pattern, point

Fruit and vegetables, point

Grains, point

Fats, point

Fish and meat, point

Dairy, point

Snacks and treats, point

Total physical activity, h/week

Clinical measurements

Body weight, $\mathrm{kg}$

Body mass index, $\mathrm{kg} / \mathrm{m}^{2}$

Waist circumference, $\mathrm{cm}$

Fasting plasma glucose, $\mathrm{mmol} / \mathrm{L}$

2-h plasma glucose, $\mathrm{mmol} / \mathrm{L}$

$\mathrm{HbA} 1 \mathrm{c}, \mathrm{mmol} / \mathrm{mol}$

Fasting plasma insulin, $\mathrm{mU} / \mathrm{L}$

Matsuda insulin sensitivity index

Total cholesterol, $\mathrm{mmol} / \mathrm{L}$

LDL cholesterol, $\mathrm{mmol} / \mathrm{L}$

HDL cholesterol, $\mathrm{mmol} / \mathrm{L}$

Triglycerides, $\mathrm{mmol} / \mathrm{L}$
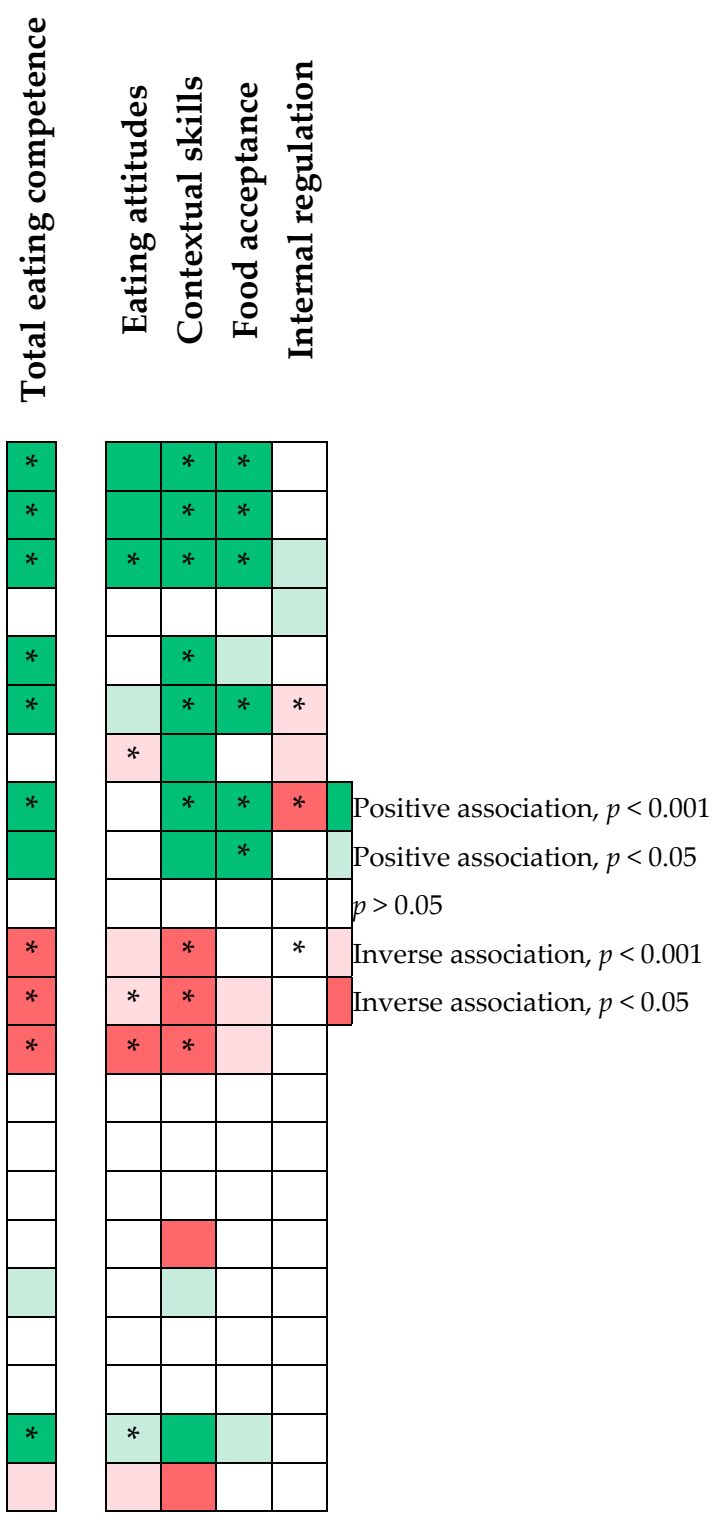

Figure 2. The associations of changes in eating competence (EC) total scores and its sub-scores with Healthy Diet Index, total physical activity and clinical measurements from linear mixed-effects models adjusted for age, sex, study province, educational level, and study group $x$ follow-up time interaction. * The associations were statistically significant after further adjustment for corresponding EC score at baseline. 2-h plasma glucose from oral glucose tolerance test.

\subsection{Change in Eating Competence Total Score Associated with Changes in Anthropometry}

An increase in the EC total score was associated with a decrease in body weight, BMI, and waist circumference adjusted for age, sex, study province and educational level (Table 2). These associations remained statistically significant after additional adjustment for the EC total score at baseline (Table 2).

3.5. Change in Eating Competence Total Score Associated with Changes in Biomarkers of Glucose and Lipid Metabolism

An increase in the EC total score was associated with an increase in MatsudaISI and HDL cholesterol concentration and a decrease in triglyceride concentration adjusted for age, sex, study province and educational level. The association with plasma HDL cholesterol, but not with MatsudaISI or triglycerides, remained statistically significant after further adjustment for the EC total score at baseline (Table 2). 


\subsection{Changes Is Eating Competence Sub-Scores Associated with Changes in Diet and Clinical Characteristics}

Increases in EC sub-scores for eating attitudes, contextual skills and food acceptance, but not internal regulation, were associated with an increase in HDI adjusted for age, sex, study province and educational level (Table A1, Figure 2). These associations, except for eating attitudes, remained statistically significant after further adjustment for EC sub-scores at baseline (Table A1). In addition, increases in contextual skills and food acceptance were associated with an increase in total physical activity (Table A1). The association of the increase in contextual skills with total physical activity was no longer statistically significant after additional adjustment for contextual skills at baseline (Table A1).

Increases in eating attitudes, contextual skills and food acceptance were associated with a decrease in BMI and waist circumference after adjustment for age, sex, study province and educational level (Table A1). In addition, increases in contextual skills and eating attitudes were associated with an increase in plasma HDL cholesterol and a decrease in triglycerides concentrations. Moreover, an increase in contextual skills was associated with a decrease in fasting plasma insulin and an increase in MatsudaISI. An increase in eating attitudes was associated with a decrease in waist circumference and an increase in HDL cholesterol, an increase in contextual skills was associated with a decrease in body weight, BMI, and waist circumference and a decrease in internal regulation was associated with an increase in body weight after further adjustment for the corresponding EC subscores at baseline (Table A1). A summary of the associations of EC and its sub-scores with outcomes adjusted for age, sex, study province and educational level is presented in Figure 2.

\section{Discussion}

This study is so far the largest to have investigated the effects of a lifestyle intervention on EC and the associations of the changes in EC with diet quality, total physical activity, anthropometrics as well as glucose and lipid metabolism. Our results show that EC slightly improved in adults with an increased risk of T2D who participated in the StopDia study, with no difference between the study groups. Enhanced EC was associated with improved diet quality, decreased body weight, BMI and waist circumference as well as increased plasma HDL cholesterol concentration, regardless of the intervention group or EC at baseline.

Our finding that improved EC was associated with reduced BMI and waist circumference is potentially important for the prevention of obesity and T2D [32,33]. Our observations are also in accordance with the inverse association between EC and BMI shown in many prior cross-sectional studies among different study populations $[7,9,10,13,15]$ as well as with the association between improved EC and weight loss found in a one-year weight management intervention [12]. Moreover, we showed, for the first time, that improved EC was prospectively associated with reduced waist circumference, improved insulin sensitivity as well as increased plasma HDL cholesterol and decreased plasma triglycerides concentrations, which are risk factors of T2D [30]. These results are in line with our previous cross-sectional observations [9]. Even a small weight loss has been shown to be beneficial for the prevention of T2D at population level [34], especially when the usual trend is weight gain $[35,36]$. If persisting, improved EC could thereby over time help reduce the risk of T2D, even though it was not associated with improved glucose metabolism in our study. Nevertheless, in our previous cross-sectional study with this same study population, better EC was associated with better glucose tolerance [9]. It is thus possible that a longer follow-up time than 1 year or greater change in adiposity would be needed to improve glucose metabolism by improved EC.

To the best of our knowledge, this is the first prospective study to show that improved EC, even regardless of the initial EC level, was associated with improved diet quality, which in turn plays a major role in the prevention of T2D [2,4]. Moreover, improved EC was associated in particular with the increased consumption of fruit and vegetables and 
improved meal frequency. These prospective results confirm the previous cross-sectional findings from the same study population [9] and, from the other study cohorts $[7,8,13]$. The observation of the association between improved EC and the increased consumption of fruit and vegetables is important since, for example in Finland, only $14 \%$ of working-age men and $22 \%$ of women consume the recommended daily amount of fruit and vegetables [37]. Moreover, the consumption of fruit and vegetables as well as dietary patterns characterized by a high consumption of vegetables have been associated with a reduced risk of obesity and T2D $[4,38,39]$. Our results thus highlight the importance of improvement in EC in lifestyle counselling aimed at preventing T2D.

Our results suggest that, in particular, changes in EC subdomains' contextual skills, characterized by having regular meals, enough time to eat and considering what kind of foods are good for oneself, as well as food acceptance, characterized by eating a diet with a wide variety of foods, including the new ones, had a beneficial influence on changes in diet quality. Furthermore, the changes in contextual skills and eating attitudes, characterized by a relaxed attitude and enjoyment of eating, had a beneficial influence on the changes in clinical measurements, including those related to weight management. The findings were consistent with our earlier cross-sectional findings [9]. Many of these behaviors and features are also those that have been associated with success in long-term weight management and in the promotion of healthy eating in the previous studies [40-42] and should, thus, be emphasized in lifestyle counselling.

The proportion of individuals defined as eating competent increased from $40 \%$ to $43 \%$ during the study, approaching the higher proportions reported in previous studies among healthy adults, ranging between $39 \%$ and $49 \%[7,8,10,13,15]$. Because the increase in EC was rather slight and seen in all study groups, also in the control group, we cannot rule out the possibility that there could have been at least some regression to the mean effect. However, the concomitant changes in EC and various outcome measures including diet quality and cardiometabolic risk factors, support the validity of the finding, although it is challenging to estimate its clinical significance. However, we suggest that if persisting, the clinical significance may increase over the years. Nonetheless, research on long-term changes in EC and its clinical meaning is needed.

It remains uncertain what kind of an intervention should be to enhance EC or its subdomains most efficiently. However, even though the content of any of the intervention groups was not specifically designed to address EC, it included contents in accordance with EC, especially with contextual skills and food acceptance, such as paying attention while eating, trying new foods and eating regularly. These themes are mentioned also in the Finnish nutrition recommendations [27] that was the basis of the written information given to the control group. Thus, as EC was improved in all study groups, including the control group, the different ways to implement or a more intense intervention did not explain the enhancement of EC. Interestingly, however, this suggests that even the mere participation in a lifestyle intervention including increased awareness of the risk of T2D, healthcare visits, receiving laboratory results and information on healthy lifestyle, can be regarded as an intervention. In fact, previous studies have shown that already a brief advice by a physician could contribute weight-related behavior change [43]. Thus, from the healthcare perspective, it is promising that such a minimal intervention could improve EC in adults at increased risk of T2D, at least among those presumably motivated to improve their health behavior.

It should be noted that the associations of improved internal regulation and eating attitudes with a decrease in some components of a healthy diet indicate that the domains of EC were differently associated with diet and health in our study population. However, the ecSI 2. $0^{\mathrm{TM}}$ contains only two items for internal regulation, which may affect its reliability. Notwithstanding this, it would be important to investigate whether all aspects of EC are needed to further promote health in adult populations, or whether some subdomains are particularly important. However, according to our results, the influence of improved EC 
is not limited to diet, but also to total physical activity, which may further mediate the beneficial associations of EC with cardiometabolic health [4,44].

The study has some strengths and limitations. As a strength, it included extensive measurements of glucose metabolism and did not only measure body weight but also waist circumference to assess abdominal adiposity. However, as a limitation it is important to note that the present study does not report the effect of the intervention on weight and glucose metabolism, because they are outcomes of the whole StopDia intervention [18] and will be reported accordingly in the paper including all study participants, also including those without EC data. As another limitation, EC was measured only twice during the study, hence short-term changes in EC could not be evaluated and we cannot rule out the possibility of reverse causality between EC and diet quality. In the future, it would be important to measure EC more frequently during the study and to have a longer follow-up. Due to the nature of the study, diet quality and physical activity were assessed by selfreported questionnaires [18,45], which may not estimate them correctly [45-47]. Moreover, diet quality was assessed by HDI [26], which, unlike food diaries, does not provide nutrientlevel information. However, our HDI was recently validated against food diaries and was shown to be feasible in healthcare and in large population-based studies [26]. It should be noted also that these results can be generalized only with caution to a general population as all participants were at increased risk of T2D, only a minority of them were men, and they were slightly more educated than Finns on average [48]. On the other hand, sex and the educational level were controlled for in the analyses making them more generalizable. Moreover, a third of Finns aged 50-59 years have a moderate risk of T2D based on the FINDRISC [48], supporting the relevance of the current study population.

\section{Conclusions}

Our results show that participation in a 1-year lifestyle intervention study conducted in healthcare can slightly enhance EC in individuals at risk of T2D, independent of the way of implementation or intensity of the intervention. Moreover, enhanced EC was associated with beneficial changes in risk factors for T2D, including improved diet quality, decreased BMI and waist circumference as well as increased plasma HDL cholesterol. These findings suggest that EC could be a potential target in lifestyle interventions aiming to improve cardiometabolic health and prevent T2D.

Author Contributions: Conceptualization, L.K., P.A., J.L., T.L. and J.P.; project administration, T.L., T.T.-T. and J.P.; funding acquisition, L.K., J.L., T.L. and J.P.; investigation, R.M., P.A. and T.T.-T.; methodology, L.K., R.M., P.A., M.K., U.S., M.H., J.L., T.L., T.T.-T. and J.P.; data curation, K.A., R.M., E.J.-R., T.L., T.T.-T. and J.P.; visualization, K.A.; formal analysis, K.A. and S.M.; writing-original draft preparation, K.A. writing—review and editing, K.A., L.K., R.M., E.J.-R., S.M., P.A., M.K., U.S., M.H., J.L., T.L., T.T.-T. and J.P. J.P. is the PI of the StopDia study. All authors have read and agreed to the published version of the manuscript.

Funding: The research was funded by the Strategic Research Council of the Academy of Finland, grant numbers 303537, 303644 and 303643 and by the Academy of Finland, grant numbers 332465, 332466 and 286028.

Institutional Review Board Statement: The StopDia study was conducted according to the guidelines of the Declaration of Helsinki and the Responsible Conduct of Research guidelines by the Finnish Advisory Board on Research Integrity and approved by the Research Ethics Committee of the Hospital District of Northern Savo (statement no: 467/2016, date 3 January 2017).

Informed Consent Statement: Written informed consent was obtained from all participants involved in the study.

Data Availability Statement: The datasets used and analyzed during the current study are available from the corresponding author on reasonable request. For data sharing inquiries, contact J.P.

Acknowledgments: We would like to acknowledge all health and social care workers in the three participating provinces (Hospital District of Northern Savo, Päijät-Häme and Southern Carelia) 
and various stakeholders for participation in planning the recruitment of the high-risk individuals and implementation of the StopDia model. We also acknowledge Kaisa Poutanen (VTT Technical Research Centre of Finland Ltd.) for conceptualization the study, Juho Viitasalo, Jussi Paananen and Juha Kekäläinen (University of Eastern Finland) for their extensive work in the development of the StopDia digital tools and Saara Vanhatalo (VTT Technical Research Centre of Finland Ltd.), Eeva Rantala (VTT Technical Research Centre of Finland Ltd.), Markus Kanerva (University of Eastern Finland/Ajatushautomo Tänk) and Riia Järvenpää (National Institute for Health and Welfare) for the recruitment of study participants and Liisa Tammela (University of Eastern Finland) for data curation and validation. We also acknowledge rest of the StopDia study group and thank the participants for their dedication and contribution to the research.

Conflicts of Interest: The authors declare no conflict of interest. The funders had no role in the design of the study; in the collection, analysis, or interpretation of data; in the writing of the manuscript, or in the decision to publish the results.

\section{Appendix A}

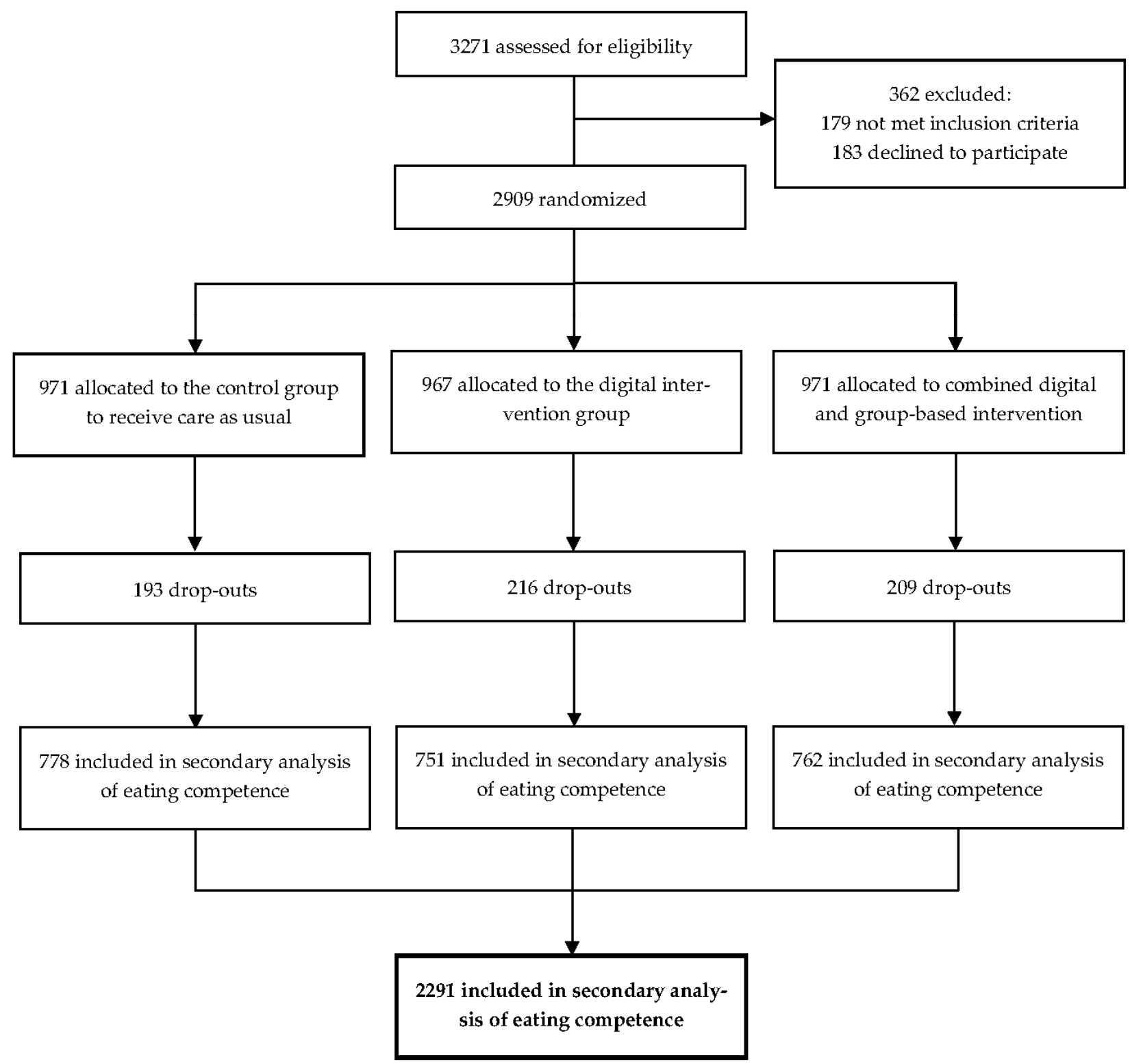

Figure A1. Flow chart describing how the study population of the present study (altogether 2291 participants, see the last row of the figure) was formed from the whole StopDia population ( $n=2909$ [18]). 
Table A1. Associations of changes in eating competence (EC) sub-scores with changes in lifestyle and metabolic factors over one year.

\begin{tabular}{|c|c|c|c|c|c|c|c|c|c|}
\hline & & Eating Attitudes & & Contextual Skills & & Food Acceptance & & Internal Regulation & \\
\hline & & $\beta(95 \% \mathrm{CI})$ & $p$ Value & $\beta(95 \% \mathrm{CI})$ & $p$ Value & $\beta(95 \% \mathrm{CI})$ & $\begin{array}{c}p \\
\text { Value }\end{array}$ & $\beta(95 \% \mathrm{CI})$ & $\begin{array}{c}p \\
\text { Value }\end{array}$ \\
\hline \multicolumn{10}{|l|}{ Diet quality } \\
\hline \multirow{2}{*}{ Healthy Diet Index } & Model 1 & $0.18(0.08$ to 0.28$)$ & $<0.001$ & $0.76(0.67$ to 0.85$)$ & $<0.001$ & $0.72(0.57$ to 0.87$)$ & $<0.001$ & $0.05(-0.14$ to 0.24$)$ & 0.611 \\
\hline & Model 2 & $0.12(-0.0002$ to 0.24$)$ & 0.050 & 0.55 (0.43 to 0.66$)$ & $<0.001$ & $0.48(0.30$ to 0.67$)$ & $<0.001$ & $0.01(-0.21$ to 0.24$)$ & 0.902 \\
\hline \multirow{2}{*}{ Meal pattern } & Model 1 & $0.03(0.02$ to 0.04$)$ & $<0.001$ & 0.08 (0.07 to 0.09$)$ & $<0.001$ & 0.05 (0.04 to 0.07 ) & $<0.001$ & $0.02(-0.004$ to 0.04$)$ & 0.114 \\
\hline & Model 2 & $0.01(-0.003$ to 0.03$)$ & 0.122 & 0.05 (0.03 to 0.06$)$ & $<0.001$ & 0.04 (0.01 to 0.06$)$ & 0.002 & $0.01(-0.02$ to 0.04$)$ & 0.343 \\
\hline \multirow{2}{*}{ Fruit and vegetables } & Model 1 & 0.14 (0.09 to 0.19$)$ & $<0.001$ & $0.38(0.33$ to 0.42$)$ & $<0.001$ & $0.42(0.35$ to 0.50$)$ & $<0.001$ & $0.13(0.03$ to 0.23$)$ & 0.010 \\
\hline & Model 2 & 0.09 (0.03 to 0.16$)$ & 0.006 & 0.26 (0.19 to 0.32$)$ & $<0.001$ & 0.23 (0.13 to 0.33$)$ & $<0.001$ & 0.11 ( -0.01 to 0.23$)$ & 0.078 \\
\hline \multirow[b]{2}{*}{ Grains } & Model 1 & $0.02(-0.03$ to 0.07$)$ & 0.392 & $0.02(-0.03$ to 0.06$)$ & 0.448 & $0.01(-0.06$ to 0.08$)$ & 0.757 & 0.12 (0.03 to 0.22$)$ & 0.007 \\
\hline & Model 2 & $0.03(-0.03$ to 0.09$)$ & 0.413 & 0.01 ( -0.04 to 0.07$)$ & 0.639 & 0.03 ( -0.06 to 0.12$)$ & 0.538 & 0.08 ( -0.03 to 0.19$)$ & 0.130 \\
\hline \multirow[b]{2}{*}{ Fats } & Model 1 & $0.01(-0.02$ to 0.04$)$ & 0.575 & 0.10 (0.07 to 0.13$)$ & $<0.001$ & 0.05 (0.0002 to 0.10$)$ & 0.049 & $0.04(-0.02$ to 0.11$)$ & 0.196 \\
\hline & Model 2 & $-0.001(-0.04$ to 0.04$)$ & 0.948 & $0.07(0.03$ to 0.11$)$ & 0.001 & $0.03(-0.03$ to 0.10$)$ & 0.350 & 0.04 ( -0.04 to 0.12$)$ & 0.330 \\
\hline \multirow{2}{*}{ Fish and meat } & Model 1 & $0.03(0.01$ to 0.05$)$ & 0.005 & 0.10 (0.08 to 0.12$)$ & $<0.001$ & 0.11 (0.09 to 0.14$)$ & $<0.001$ & $-0.06(-0.10$ to -0.02$)$ & 0.002 \\
\hline & Model 2 & $0.02(-0.005$ to 0.04$)$ & 0.126 & $0.07(0.05$ to 0.10$)$ & $<0.001$ & 0.04 (0.006 to 0.08$)$ & 0.022 & $-0.07(-0.11$ to -0.02$)$ & 0.003 \\
\hline \multirow{2}{*}{ Dairy } & Model 1 & $-0.03(-0.05$ to -0.01$)$ & 0.001 & $0.04(0.02$ to 0.06$)$ & $<0.001$ & 0.004 ( -0.03 to 0.03$)$ & 0.814 & $-0.07(-0.11$ to -0.03$)$ & 0.001 \\
\hline & Model 2 & $-0.03(-0.06$ to -0.002$)$ & 0.037 & $0.02(-0.005$ to 0.05$)$ & 0.103 & $0.01(-0.04$ to 0.05$)$ & 0.736 & $-0.04(-0.09$ to 0.01$)$ & 0.116 \\
\hline \multirow{2}{*}{ Snacks and treats } & Model 1 & $0.003(-0.02$ to 0.03$)$ & 0.832 & $0.10(0.08$ to 0.12$)$ & $<0.001$ & 0.09 (0.06 to 0.13$)$ & $<0.001$ & $-0.12(-0.17$ to -0.07$)$ & $<0.001$ \\
\hline & Model 2 & $0.01(-0.02$ to 0.04$)$ & 0.435 & 0.09 (0.06 to 0.12$)$ & $<0.001$ & 0.10 (0.05 to 0.14$)$ & $<0.001$ & $-0.10(-0.16$ to -0.05$)$ & $<0.001$ \\
\hline \multicolumn{10}{|l|}{ Physical activity } \\
\hline \multirow{2}{*}{ Total physical activity, h/week } & Model 1 & $0.04(-0.06$ to 0.14$)$ & 0.417 & 0.24 (0.14 to 0.33$)$ & $<0.001$ & $0.36(0.22$ to 0.51$)$ & $<0.001$ & $-0.11(-0.31$ to 0.08$)$ & 0.257 \\
\hline & Model 2 & $-0.02(-0.15$ to 0.11$)$ & 0.764 & 0.12 (-0.01 to 0.25$)$ & 0.070 & $0.27(0.07$ to 0.47$)$ & 0.009 & $-0.16(-0.40$ to 0.09$)$ & 0.209 \\
\hline \multicolumn{10}{|l|}{ Anthropometry } \\
\hline \multirow{2}{*}{ Body weight, kg } & Model 1 & $-0.08(-0.14$ to -0.02$)$ & 0.009 & $-0.17(-0.23$ to -0.11$)$ & $<0.001$ & $-0.09(-0.18$ to 0.004$)$ & 0.061 & 0.10 (-0.01 to 0.21$)$ & 0.075 \\
\hline & Model 2 & $-0.06(-0.12$ to 0.01$)$ & 0.072 & $-0.13(-0.19$ to -0.07$)$ & $<0.001$ & $-0.08(-0.18$ to 0.02$)$ & 0.113 & $0.12(0.002$ to 0.23$)$ & 0.046 \\
\hline \multirow{2}{*}{ Body mass index, $\mathrm{kg} / \mathrm{m}^{2}$} & Model 1 & $-0.04(-0.06$ to -0.01$)$ & 0.001 & $-0.07(-0.09$ to -0.04$)$ & $<0.001$ & $-0.04(-0.07$ to -0.001$)$ & 0.041 & $0.03(-0.01$ to 0.07$)$ & 0.111 \\
\hline & Model 2 & $-0.02(-0.05$ to $<-0.001)$ & 0.050 & $-0.05(-0.07$ to -0.02$)$ & $<0.001$ & $-0.03(-0.06$ to 0.01$)$ & 0.121 & $0.04(-0.0002$ to 0.08$)$ & 0.051 \\
\hline \multirow{2}{*}{ Waist circumference, $\mathrm{cm}$} & Model 1 & $-0.18(-0.26$ to -0.10$)$ & $<0.001$ & $-0.24(-0.32$ to -0.17$)$ & $<0.001$ & $-0.17(-0.29$ to -0.05$)$ & 0.005 & $0.09(-0.05$ to 0.23$)$ & 0.226 \\
\hline & Model 2 & $-0.13(-0.21$ to -0.05$)$ & 0.002 & $-0.15(-0.23$ to -0.07$)$ & $<0.001$ & -0.12 ( -0.25 to 0.003$)$ & 0.056 & $0.12(-0.03$ to 0.27$)$ & 0.115 \\
\hline \multicolumn{10}{|l|}{ Glucose metabolism } \\
\hline \multirow{2}{*}{ Fasting plasma glucose, $\mathrm{mmol} / \mathrm{L}$} & Model 1 & $-0.001(-0.01$ to 0.004$)$ & 0.579 & $-0.002(-0.01$ to 0.003$)$ & 0.375 & $0.003(-0.01$ to 0.01$)$ & 0.509 & $0.002(-0.01$ to 0.01$)$ & 0.729 \\
\hline & Model 2 & 0.002 ( -0.005 to 0.01$)$ & 0.506 & $0.002(-0.005$ to 0.01$)$ & 0.577 & 0.004 ( -0.01 to 0.01$)$ & 0.506 & $0.003(-0.01$ to 0.02$)$ & 0.596 \\
\hline \multirow{2}{*}{ 2-h plasma glucose from OGTT, mmol/L } & Model 1 & $-0.005(-0.02$ to 0.01$)$ & 0.567 & $0.003(-0.01$ to 0.02$)$ & 0.749 & $-0.02(-0.04$ to 0.01$)$ & 0.278 & $-0.01(-0.04$ to 0.03$)$ & 0.768 \\
\hline & Model 2 & $0.005(-0.02$ to 0.03$)$ & 0.704 & $0.02(-0.004$ to 0.04$)$ & 0.111 & $-0.02(-0.05$ to 0.02$)$ & 0.342 & 0.02 ( -0.03 to 0.06$)$ & 0.459 \\
\hline \multirow{2}{*}{$\mathrm{HbA1c}, \mathrm{mmol} / \mathrm{mol}$} & Model 1 & $-0.02(-0.05$ to 0.02$)$ & 0.385 & $-0.03(-0.07$ to 0.002$)$ & 0.064 & $0.001(-0.05$ to 0.05$)$ & 0.973 & $0.01(-0.06$ to 0.08$)$ & 0.701 \\
\hline & Model 2 & $-0.02(-0.07$ to 0.02$)$ & 0.346 & $-0.02(-0.07$ to 0.02$)$ & 0.314 & $0.04(-0.03$ to 0.11$)$ & 0.240 & $0.01(-0.08$ to 0.09$)$ & 0.903 \\
\hline \multirow{2}{*}{ Fasting plasma insulin, mU/L } & Model 1 & $0.02(-0.09$ to 0.13$)$ & 0.729 & $-0.20(-0.31$ to -0.09$)$ & $<0.001$ & $-0.13(-0.29$ to 0.04$)$ & 0.127 & $0.09(-0.13$ to 0.31$)$ & 0.402 \\
\hline & Model 2 & $0.08(-0.08$ to 0.23$)$ & 0.333 & $0.03(-0.13$ to 0.18$)$ & 0.737 & $-0.02(-0.26$ to 0.22$)$ & 0.887 & $0.06(-0.23$ to 0.34$)$ & 0.686 \\
\hline Matsuda insulin sensitivity index & Model 1 & 0.06 (-0.01 to 0.14$)$ & 0.115 & $0.13(0.05$ to 0.20$)$ & 0.001 & 0.06 (-0.06 to 0.17$)$ & 0.322 & $0.02(-0.13$ to 0.17$)$ & 0.807 \\
\hline Matsuda insuin sensitrvity index & Model 2 & 0.05 ( -0.05 to 0.14$)$ & 0.313 & 0.03 ( -0.07 to 0.12 ) & 0.574 & $0.02(-0.13$ to 0.16$)$ & 0.802 & $0.04(-0.14$ to 0.21$)$ & 0.681 \\
\hline Lipid metabolism & & & & & & & & & \\
\hline Total cholesterol mmol/I & Model 1 & $-0.0002(-0.01$ to 0.01$)$ & 0.960 & $-0.002(-0.01$ to 0.01$)$ & 0.578 & $0.01(-0.004$ to 0.02$)$ & 0.193 & $0.02(-0.002$ to 0.03$)$ & 0.075 \\
\hline Iotal cholesterol, mmol/L & Model 2 & -0.003 ( -0.01 to 0.01$)$ & 0.579 & $-0.01(-0.02$ to 0.01$)$ & 0.293 & $0.01(-0.01$ to 0.02$)$ & 0.430 & $0.01(-0.01$ to 0.03$)$ & 0.388 \\
\hline & Model 1 & $-0.002(-0.01$ to 0.01$)$ & 0.585 & $-0.004(-0.01$ to 0.004$)$ & 0.368 & 0.01 (-0.01 to 0.02$)$ & 0.288 & $0.01(-0.005$ to 0.03$)$ & 0.173 \\
\hline LDL cholesterol, mmol/L & Model 2 & $-0.01(-0.02$ to 0.004$)$ & 0.244 & $-0.004(-0.01$ to 0.01$)$ & 0.417 & 0.01 ( -0.01 to 0.02$)$ & 0.503 & $0.004(-0.02$ to 0.02$)$ & 0.712 \\
\hline & Model 1 & 0.005 (0.002 to 0.01$)$ & 0.001 & 0.01 (0.002 to 0.01$)$ & $<0.001$ & 0.004 (0.0002 to 0.01$)$ & 0.040 & $0.0004(-0.005$ to 0.01$)$ & 0.877 \\
\hline HDL cholesterol, mmol/L & Model 2 & 0.005 (0.002 to 0.01$)$ & 0.001 & $0.003(-0.0005$ to 0.01$)$ & 0.093 & $0.004(-0.001$ to 0.01$)$ & 0.129 & $0.001(-0.005$ to 0.01$)$ & 0.708 \\
\hline Triglycerides, mmol/L & Model 1 & $-0.01(-0.01$ to -0.0001$)$ & 0.048 & $-0.01(-0.02$ to -0.01$)$ & $<0.001$ & $-0.01(-0.02$ to 0.003$)$ & 0.279 & $0.01(-0.003$ to 0.02$)$ & 0.126 \\
\hline & Model 2 & -0.004 ( -0.01 to 0.004$)$ & 0.317 & $-0.01(-0.01$ to 0.002$)$ & 0.163 & $0.003(-0.01$ to 0.02$)$ & 0.663 & $0.01(-0.002$ to 0.03$)$ & 0.095 \\
\hline
\end{tabular}

The data are regression coefficients $(\beta)$ and their $95 \%$ confidence intervals $(\mathrm{CI})$ for changes in EC sub-scores from linear mixed-effects models and p-values for EC sub-scores; Model 1 was adjusted for age, sex, study province, educational level, and study group x follow-up time interaction (follow-up time between nurse visits, filling out questionnaires or laboratory visits). Measures of lipid metabolism were also adjusted for cholesterol-lowering medication; Model 2 was additionally adjusted for corresponding EC sub-scores at baseline.

\section{References}

1. Tuomilehto, J.; Lindström, J.; Eriksson, J.G.; Valle, T.T.; Hämäläinen, H.; Ilanne-Parikka, P.; Keinänen-Kiukaanniemi, S.; Laakso, M.; Louheranta, A.; Rastas, M.; et al. Prevention of type 2 diabetes mellitus by changes in lifestyle among subjects with impaired glucose tolerance. N. Engl. J. Med. 2001, 344, 1343-1350. [CrossRef]

2. Merlotti, C.; Morabito, A.; Pontiroli, A.E. Prevention of type 2 diabetes; a systematic review and meta-analysis of different intervention strategies. Diabetes Obes. Metab. 2014, 16, 719-727. [CrossRef] [PubMed]

3. Afshin, A.; Sur, P.J.; Fay, K.A.; Cornaby, L.; Ferrara, G.; Salama, J.S.; Mullany, E.C.; Abate, K.H.; Abbafati, C.; Abebe, Z.; et al. Health effects of dietary risks in 195 countries, 1990-2017: A systematic analysis for the Global Burden of Disease Study 2017. Lancet 2019, 393, 1958-1972. [CrossRef]

4. Uusitupa, M.; Khan, T.A.; Viguiliouk, E.; Kahleova, H.; Rivellese, A.A.; Hermansen, K.; Pfeiffer, A.; Thanopoulou, A.; SalasSalvadó, J.; Schwab, U.; et al. Prevention of type 2 diabetes by lifestyle changes: A systematic review and meta-analysis. Nutrients 2019, 11, 2611. [CrossRef] [PubMed] 
5. $\quad$ Lindström, J.; Peltonen, M.; Eriksson, J.G.; Ilanne-Parikka, P.; Aunola, S.; Keinänen-Kiukaanniemi, S.; Uusitupa, M.; Tuomilehto, J. Improved lifestyle and decreased diabetes risk over 13 years: Long-term follow-up of the randomised Finnish Diabetes Prevention Study (DPS). Diabetologia 2013, 56, 284-293. [CrossRef] [PubMed]

6. Satter, E. Eating Competence: Definition and evidence for the Satter Eating Competence Model. J. Nutr. Educ. Behav. 2007, 39, S142-S153. [CrossRef]

7. Lohse, B.; Satter, E.; Horacek, T.; Gebreselassie, T.; Oakland, M.J. Measuring eating competence: Psychometric properties and validity of the ecSatter inventory. J. Nutr. Educ. Behav. 2007, 39, S154-S166. [CrossRef]

8. Lohse, B.; Psota, T.; Estruch, R.; Zazpe, I.; Sorli, J.V.; Salas-Salvado, J.; Serra, M.; Krall, J.S.; Marquez, F.; Ros, E. Eating competence of elderly Spanish adults is associated with a healthy diet and a favorable cardiovascular disease risk profile. J. Nutr. 2010, 140, 1322-1327. [CrossRef] [PubMed]

9. Tilles-Tirkkonen, T.; Aittola, K.; Männikkö, R.; Absetz, P.; Kolehmainen, M.; Schwab, U.; Lindström, J.; Lakka, T.; Pihlajamäki, J.; Karhunen, L. Eating competence is associated with lower prevalence of obesity and better insulin sensitivity in Finnish adults with increased risk for type 2 diabetes: The StopDia study. Nutrients 2020, 12, 104. [CrossRef]

10. Krall, J.S.; Lohse, B. Validation of a measure of the Satter Eating Competence Model with low-income females. Int. J. Behav. Nutr. Phys. Act. 2011, 8, 26. [CrossRef]

11. Lohse, B.; Bailey, R.L.; Krall, J.S.; Wall, D.E.; Mitchell, D.C. Diet quality is related to eating competence in cross-sectional sample of low-income females surveyed in Pennsylvania. Appetite 2012, 58, 645-650. [CrossRef]

12. Lohse, B.; Krall, J.S.; Psota, T.; Kris-Etherton, P. Impact of a Weight management intervention on eating competence: Importance of measurement interval in protocol design. Am. J. Health Promot. 2018, 32, 718-728. [CrossRef]

13. De Queiroz, F.L.N.; Nakano, E.Y.; Botelho, R.B.A.; Ginani, V.C.; Cançado, A.L.F.; Zandonadi, R.P. Eating competence associated with food consumption and health outcomes among Brazilian adult population. Nutrients 2020, 12, 3218. [CrossRef] [PubMed]

14. Clifford, D.; Keeler, L.A.; Gray, K.; Steingrube, A.; Morris, M.N. Weight attitudes predict eating competence among college students. Fam. Consum. Sci. Res. J. 2010, 39, 184-193. [CrossRef]

15. Quick, V.; Shoff, S.; Lohse, B.; White, A.; Horacek, T.; Greene, G. Relationships of eating competence, sleep behaviors and quality, and overweight status among college students. Eat. Behav. 2015, 19, 15-19. [CrossRef]

16. Bloom, L.; Shelton, B.; Bengough, M.; Brennan, L. Psychosocial outcomes of a non-dieting based positive body image community program for overweight adults: A pilot study. J. Eat. Disord. 2013, 1, 44. [CrossRef] [PubMed]

17. Järvelä-Reijonen, E.; Karhunen, L.; Sairanen, E.; Muotka, J.; Lindroos, S.; Laitinen, J.; Puttonen, S.; Peuhkuri, K.; Hallikainen, M.; Pihlajamäki, J.; et al. The effects of acceptance and commitment therapy on eating behavior and diet delivered through face-to-face contact and a mobile app: A randomized controlled trial. Int. J. Behav. Nutr. Phys. Act. 2018, 15, 1-14. [CrossRef]

18. Pihlajamäki, J.; Männikkö, R.; Tilles-Tirkkonen, T.; Karhunen, L.; Kolehmainen, M.; Schwab, U.; Lintu, N.; Paananen, J.; Järvenpää, R.; Harjumaa, M.; et al. Digitally supported program for type 2 diabetes risk identification and risk reduction in real-world setting: Protocol for the StopDia model and randomized controlled trial. BMC Public Health 2019, 19, 255. [CrossRef]

19. Lindström, J.; Tuomilehto, J. The diabetes risk score: A practical tool to predict type 2 diabetes risk. Diabetes Care 2003, 26, 725-731. [CrossRef]

20. Harjumaa, M.; Absetz, P.; Ermes, M.; Mattila, E.; Männikkö, R.; Tilles-Tirkkonen, T.; Lintu, N.; Schwab, U.; Umer, A.; Leppänen, J.; et al. Internet-based lifestyle intervention to prevent type 2 diabetes through healthy habits: Design and 6-month usage results of randomized controlled trial. JMIR Diabetes 2020, 5, e15219. [CrossRef]

21. Stotts, J.L.; Lohse, B. Reliability of the ecSatter inventory as a tool to measure eating competence. J. Nutr. Educ. Behav. 2007, 39, S167-S170. [CrossRef]

22. Lohse, B. The Satter Eating Competence Inventory for Low-income persons is a valid measure of eating competence for persons of higher socioeconomic position. Appetite 2015, 87, 223-228. [CrossRef]

23. Krall, J.S.; Lohse, B. Cognitive testing with female nutrition and education assistance program participants informs validity of the Satter Eating Competence Inventory. J. Nutr. Educ. Behav. 2010, 42, 277-283. [CrossRef]

24. Järvelä-Reijonen, E.; Karhunen, L.; Sairanen, E.; Rantala, S.; Laitinen, J.; Puttonen, S.; Peuhkuri, K.; Hallikainen, M.; Juvonen, K.; Myllymäki, T.; et al. High perceived stress is associated with unfavorable eating behavior in overweight and obese Finns of working age. Appetite 2016, 103, 249-258. [CrossRef]

25. Godleski, S.; Lohse, B.; Krall, J.S. Satter Eating Competence Inventory subscale restructure after confirmatory factor analysis. J. Nutr. Educ. Behav. 2019, 51, 1003-1010. [CrossRef]

26. Lindström, J.; Aittola, K.; Pölönen, A.; Hemiö, K.; Ahonen, K.; Karhunen, L.; Männikkö, R.; Siljamäki-Ojansuu, U.; TillesTirkkonen, T.; Virtanen, E.; et al. Formation and validation of the Healthy Diet Index (HDI) for evaluation of diet quality in healthcare. Int. J. Environ. Res. Public Health 2021, 18, 2362. [CrossRef]

27. VRN Valtion Ravitsemusneuvottelukunta. Terveyttä Ruoasta-Suomalaiset Ravitsemussuositukset 2014, 5th ed.; Valtion Ravitsemusneuvottelukunta: Helsinki, Finland, 2018; pp. 1-56.

28. Matsuda, M.; DeFronzo, R.A. Insulin sensitivity indices obtained from oral glucose tolerance testing: Comparison with the euglycemic insulin clamp. Diabetes Care 1999, 22, 1462-1470. [CrossRef] [PubMed]

29. Stancakova, A.; Javorsky, M.; Kuulasmaa, T.; Haffner, S.M.; Kuusisto, J.; Laakso, M. Changes in insulin sensitivity and insulin release in relation to glycemia and glucose tolerance in 6,414 Finnish men. Diabetes 2009, 58, 1212-1221. [CrossRef] [PubMed] 
30. Association, A.D. Classification and diagnosis of diabetes: Standards of Medical Care in Diabetes-2020. Diabetes Care 2020, 43, S14-S31. [CrossRef] [PubMed]

31. Harris, P.A.; Taylor, R.; Thielke, R.; Payne, J.; Gonzalez, N.; Conde, J.G. Research electronic data capture (REDCap)-a metadatadriven methodology and workflow process for providing translational research informatics support. J. Biomed. Inform. 2009, 42, 377-381. [CrossRef] [PubMed]

32. Lee, D.H.; Keum, N.; Hu, F.B.; Orav, E.J.; Rimm, E.B.; Willett, W.C.; Giovannucci, E.L. Comparison of the association of predicted fat mass, body mass index, and other obesity indicators with type 2 diabetes risk: Two large prospective studies in US men and women. Eur. J. Epidemiol. 2018, 33, 1113-1123. [CrossRef] [PubMed]

33. Bellou, V.; Belbasis, L.; Tzoulaki, I.; Evangelou, E. Risk factors for type 2 diabetes mellitus: An exposure-wide umbrella review of meta-analyses. PLoS ONE 2018, 13, e0194127. [CrossRef] [PubMed]

34. Galaviz, K.I.; Weber, M.B.; Straus, A.; Haw, J.S.; Venkat Narayan, K.M.; Ali, M.K. Global diabetes prevention interventions: A systematic review and network meta-analysis of the real-world impact on incidence, weight, and glucose. Diabetes Care 2018, 41, 1526-1534. [CrossRef] [PubMed]

35. Pajunen, P.; Vartiainen, E.; Männistö, S.; Jousilahti, P.; Laatikainen, T.; Peltonen, M. Intra-individual changes in body weight in population-based cohorts during four decades: The Finnish FINRISK study. Eur. J. Public Health 2012, 22, 107-112. [CrossRef] [PubMed]

36. Di Cesare, M.; Bentham, J.; Stevens, G.A.; Zhou, B.; Danaei, G.; Lu, Y.; Bixby, H.; Cowan, M.J.; Riley, L.M.; Hajifathalian, K.; et al. Trends in adult body-mass index in 200 countries from 1975 to 2014: A pooled analysis of 1698 population-based measurement studies with 19.2 million participants. Lancet 2016, 387, 1377-1396.

37. alsta, L.; Kaartinen, N.; Tapanainen, H.; Männistö, S. (Eds.) Nutrition in Finland-The National FinDiet 2017 Survey; Report 12/2018; Institute for Health and Welfare (THL): Helsinki, Finland, 2018; pp. 1-239.

38. Schwingshackl, L.; Hoffmann, G.; Lampousi, A.M.; Knüppel, S.; Iqbal, K.; Schwedhelm, C.; Bechthold, A.; Schlesinger, S.; Boeing, H. Food groups and risk of type 2 diabetes mellitus: A systematic review and meta-analysis of prospective studies. Eur. J. Epidemiol. 2017, 32, 363-375. [CrossRef]

39. Schlesinger, S.; Neuenschwander, M.; Schwedhelm, C.; Hoffmann, G.; Bechthold, A.; Boeing, H.; Schwingshackl, L. Food groups and risk of overweight, obesity, and weight gain: A systematic review and dose-response meta-analysis of prospective studies. Adv. Nutr. 2019, 10, 205-218. [CrossRef]

40. Kärkkäinen, U.; Mustelin, L.; Raevuori, A.; Kaprio, J.; Keski-Rahkonen, A. Successful weight maintainers among young adults—A ten-year prospective population study. Eat. Behav. 2018, 29, 91-98. [CrossRef]

41. Larsen, S.C.; Heitmann, B.L. More frequent intake of regular meals and less frequent snacking are weakly associated with lower long-term gains in body mass index and fat mass in middle-aged men and women. J. Nutr. 2019, 149, 824-830. [CrossRef]

42. Bédard, A.; Lamarche, P.O.; Grégoire, L.M.; Trudel-Guy, C.; Provencher, V.; Desroches, S.; Lemieux, S. Can eating pleasure be a lever for healthy eating? A systematic scoping review of eating pleasure and its links with dietary behaviors and health. PLoS ONE 2021, 15, e0244292. [CrossRef]

43. Rose, S.A.; Poynter, P.S.; Anderson, J.W.; Noar, S.M.; Conigliaro, J. Physician weight loss advice and patient weight loss behavior change: A literature review and meta-analysis of survey data. Int. J. Obes. 2013, 37, 118-128. [CrossRef] [PubMed]

44. Battista, F.; Ermolao, A.; Baak, M.A.; van Beaulieu, K.; Blundell, J.E.; Busetto, L.; Carraça, E.V.; Encantado, J.; Dicker, D.; FarpourLambert, N.; et al. Effect of exercise on cardiometabolic health of adults with overweight or obesity: Focus on blood pressure, insulin resistance, and intrahepatic fat-A systematic review and meta-analysis. Obes. Rev. 2021, 22, e13269. [CrossRef] [PubMed]

45. Hemiö, K.; Pölönen, A.; Ahonen, K.; Kosola, M.; Viitasalo, K.; Lindström, J. A simple tool for diet evaluation in primary health care: Validation of a 16-item food intake questionnaire. Int. J. Environ. Res. Public Health 2014, 11, 2683-2697. [CrossRef] [PubMed]

46. Dowd, K.P.; Szeklicki, R.; Minetto, M.A.; Murphy, M.H.; Polito, A.; Ghigo, E.; Ploeg, H.; van der Ekelund, U.; Maciaszek, J.; Stemplewski, R.; et al. A systematic literature review of reviews on techniques for physical activity measurement in adults: A DEDIPAC study. Int. J. Behav. Nutr. Phys. Act. 2018, 15, 1-13. [CrossRef] [PubMed]

47. Burrows, T.L.; Ho, Y.Y.; Rollo, M.E.; Collins, C.E. Validity of dietary assessment methods when compared to the method of doubly labeled water: A systematic review in adults. Front. Endocrinol. 2019, 10, 850. [CrossRef] [PubMed]

48. Koponen, P.; Borodulin, K.; Lundqvist, A.; Sääksjärvi, K.; Koskinen, S. Health, Functional Capacity and Welfare in Finland-Fin Health 2017 Study; Report 4/2018; National Institute for Health and Welfare (THL): Helsinki, Finland, 2018; pp. 1-236. 